(C) 1983. The Genetical Society of Great Britain

\title{
COMPLEX HYBRIDITY IN ISOTOMA PETRAEA V. ALLOZYME VARIATION AND THE PURSUIT OF HYBRIDITY
}

\author{
S. H. JAMES, * A. P. WYLIE, $†$ M. S. JOHNSON \\ S. A. CARSTAIRS* AND G. A. SIMPSON* \\ * Department of Botany, University of Western Australia, Nedlands, 6009, Australia; \\ $\dagger$ Department of Botany, University of Otago, Dunedin, New Zealand; \\ $\ddagger$ Department of Zoology, University of Western Australia, Nedlands, 6009, Australia
}

Received 13.vi.83

\section{SUMMARY}

\begin{abstract}
Isoenzyme analysis of 12 structurally homozygous and 24 complex hybrid population samples of Isotoma petraea for ten enzyme systems revealed 9 polymorphic and 4 monomorphic loci. The structurally homozygous populations were relatively depauperate in allozyme heterozygotes so that rare alleles occurred more frequently as homozygous rather than heterozygous genotypes. The complex hybrid populations exhibited high levels of fixed allozymic hybridity and were $12 \cdot 5$ times as heterozygous at these loci as were the structural homozygotes. The distribution of allozymic variability supports the theory that complex hybridity in Isotoma originated on Pigeon Rock and migrated through the Isotoma population system to the south-west. Evidence was also adduced that du ring the evolution of the larger ringed complex hybrids, allozyme homozygosity sometimes replaced allozyme heterozygosity although the segments which carried these loci remained, indubitably, in fixed heterozygosity.
\end{abstract}

\section{INTRODUCTION}

Isotoma petraea is a herbaceous perennial and mainly self-pollinating member of the Lobeliaceae endemic to granite outcrops and other rocky areas throughout the Eremaean Province of Australia. The species is of particular interest in that, in the south-western corner of its distributional range, it has evolved complex hybridity (James 1965, 1970). It exists in small isolated populations between which there is little migration. Complex hydridity evidently arose on Pigeon Rock, a large granite outcrop some $145 \mathrm{~km}$ north of Southern Cross in Western Australia. The genetic system has spread from that location in a generally south-westerly direction so that the multiple interchange ring, initially $\odot 6$ at Pigeon Rock, has enlarged through a sequence of intermediate sizes, to $\odot 14$ in extreme south-westerly populations.

The evolution of complex hybridity in Isotoma has been taken to represent a clear demonstration of natural selection acting as a force directing the orthogenetic assembly of increasingly conservative devices in a "pursuit of hybridity" (Darlington 1958), following the adoption of an autogamous breeding mechanism (James 1965, 1970).

Levy and Levin (1975) point out that there is "general agreement that complex structural hybridity arose as a mechanism that preserves or accumulates genic heterozygosity in unspecific or hybridising populations originally

Previous paper in series: Beltran, I. C. and S. H. James (1974), Complex Hydridity in Isotoma petraea. IV. heterosis in interpopulational hybrids. Aust. J. Bot. 22, 251-264. 
adapted to outbreeding but more recently subject to inbreeding by virtue of self-compatibility or small population size.... Therefore, relative to bivalent forms, structurally heterozygous species ought to be highly heterozygous genetically and, correlatively, should exhibit a large proportion of polymorphic loci with a rich array of alleleic variants". Their analysis of allozyme variation in the Oenothera biennis complex, however, showed that "When compared to plant species in general, the permanent translocation heterozygotes ... are genically depauperate and display only moderate levels of genic heterozygosity" although individual lineages were able "to maintain genic heterozygosity in spite of enforced self-fertilisation for more than 20 generations" in culture. They conclude that "This ability, rather than extraordinarily high levels of heterozygosity per se, distinguishes the ring-forming oenotheras from typical self-fertilising plants"'.

Levin (1975) suggests that "The advent of electrophoretic techniques has permitted the testing of long-standing hypothesis in Oenothera and it is evident that some foregone conclusions about gene-chromosome relationships need to be reconsidered".

Levy and Levin (1975) "view the origin of complex structural hybridity in Oenothera as the result of selection for increased fertility in areas of hybridisation between taxa differing by several segmental arrangements. The greatest fertility and thus fitness would accrue to hybrids which had the lowest incidence of duplicate and deficient gametes". They suggest that "The view that complex structural hybridity is a means to escape sterility is consistent with the depauperate gene pools of each species and the $O e$. biennis complex as a whole, the high level of genetic identity among taxa, and the large number of homogyzous ring-forming strains".

On the other hand, the evolution of complex hybridity in Isotoma petraea has been interpreted, holistically, in terms of a "pursuit of hybridity" (vide supra). Heterozygote advantage would appear to be the only basis upon which natural selection could displace apparently fully fertile structural homozygotes with ring-of-fourteen complex heterozygotes exhibiting 90 per cent sterility (James, 1970). The very high levels of sterility in Isotoma complex hybrids would certainly seem to preclude an "escape from sterility" as a basis for their selective advantage.

In this paper, starch gel electrophoretic procedures for 10 enzyme systems in Isotoma are reported. They permit the identification of 13 loci, of which 9 were polymorphic. Two cases of electrophenotypic variation which may be due to post-translational effects are noted. These techniques enabled a useful comparison of the genetic variation in primitive structural homozygote populations with that of their complex hybrid derivatives, and indicate a basis for compromise between the two contending evolutionary hypotheses.

\section{MATERIAL AND METHODS}

A collection of 490 plants from 36 south-western populations of Isotoma petraea was grown from cuttings under ambient glasshouse conditions, but in a few cases, seedling progenies were used in place of field collected cutting material.

A single young unopened flower bud (diploid tissue) or the pollen from 3 to 6 freshly opened flowers (haploid tissue) was homogenised in $7 \cdot 5 \mu \mathrm{l}$ 
of 10 per cent sucrose containing 0.5 per cent bromo-phenol blue and a trace of Cleland's reagent (DTT: dithioerythritol) in microtitration wells at about $0-4^{\circ} \mathrm{C}$. Homogenates were absorbed into $6 \times 4 \mathrm{~mm}$ Whatman No. 1 Chromatography paper wicks, blotted on filter paper and inserted into 12.5 per cent starch gels (Electrostarch or Connaught) for flat-bed electrophoresis. The gels supported an ice tray for additional cooling and were run in a refrigerator at $4^{\circ} \mathrm{C}$ until the dye front had moved about $8 \mathrm{~cm}$.

Two buffer systems were used

(a) Lithium borate: modified from buffer system 2. Lithium hydroxide, Selander et al., (1971).

Electrode buffer: $0 \cdot 19 \mathrm{M}$ boric acid, $0.03 \mathrm{M}$ Lithium hydroxide.

Gel buffer: $0.45 \mathrm{M}$ Tris, $0 \cdot 072 \mathrm{M}$ citric acid.

Gel: combine $35 \mathrm{ml}$ of Gel buffer and $15 \mathrm{ml}$ of Electrode buffer with water to $250 \mathrm{ml} .250 \mathrm{~V}, 80 \mathrm{~mA}$.

(GOT, LAP, EST, PGI).

(b) Tris citrate: modified from buffer system 4. Continuous tris citrate, Selander et al., (1971).

Electrode buffer: $0.223 \mathrm{M}$ Tris, $0.086 \mathrm{M}$ citric acid, $0.01 \mathrm{M} \mathrm{MgCl}_{2}$, $\mathrm{pH} 7 \cdot 0$.

Gel: $1: 8 \cdot 5$ dilution of electrode buffer. $150 \mathrm{~V}, 80 \mathrm{~mA}$.

(ADH, GDH, IDH, PGM, 6PGD, ShDH).

All the enzymes demonstrated in these studies migrate anodally. Specific staining for activity within the gel was obtained using the recipes of Shaw and Prasad (1979) except that 1 per cent agar overlays were used instead of liquid incubations in all assays using tetrazolium salts apart from GDH. Invariably, we used MTT (3-(4,5-dimethyl thiazolyl-2)-2,5-diphenyl tetrazolium bromide) as the tetrazolium salt. $\mathrm{ShDH}$ was assayed by the method in Linhart et al., (1981).

Following staining, overlain gels were stopped by smearing with 45 per cent acetic acid. Gels were fixed for 30 minutes by immersion in 7 per cent acetic acid, washed in distilled water, impregnated with 5 per cent glycerol for 30 minutes, wrapped in cellophane and dried according to the method of Numachi (1981) as permanent records.

\section{RESULTS AND INTERPRETATIONS}

(i) The enzyme systems used

(a) PGI (Phosphoglucoisomerase): This enzyme regularly displayed two zones of activity in diploid tissue and pollen homogenates, corresponding to two loci,.,PGI-1 and PGI-2. Both loci were monomorphic.

(b) $A D H$ (Alcohol dehydrogenase): ADH phenotypes consist of a single band at either of two positions, or two bands, one at each position, in both diploid and haploid materials. The enzyme appears to be more abundant in pollen than in bud homogenates. ADH in Isotoma is a monomeric enzyme coded by a single locus at which we have observed two alleles.

(c) GOT (Glutamate oxaloacetate transaminase): GOT isoenzymes are coded by 4 loci in this material (fig. 1). GOT-1, the fastest, is 
expressed in both diploid tissue and pollen, and is presumably of cytoplasmic occurrence. It is polymorphic, with 3 alleles being recorded, the fastest being $G O T-11$. Heterozygotes produce a blurred zone of activity because of their heteromer products, but those of $G O T-1(1 / 3)$ which combine the most widely spaced allozymes, exhibit a fairly distinct middle band in diploid zymograms. In pollen zymograms, the middle band is not present due to meiotic segregation (Weeden and Gottlieb, 1979). Hence GOT-1 is a cytoplasmic dimeric enzyme, encoded by a locus at which we have observed 3 alleles.

$G O T-2$. This locus is expressed in diploid tissue, but not in pollen. The enzyme therefore probably occurs in the chloroplast. Three alleles have been observed. GOT-2 1 comigrates with $G O T-13$, and GOT-2 3 comigrates with GOT-1 2. GOT-2 is also a dimeric protein.

GOT-3. This isoenzyme was invariant, expressed in both diploid and haploid tissues and is evidently encoded by a single monomorphic locus.

$G O T-4$. This isoenzyme is weakly and unreliably expressed in our zymograms; it is very slowly moving, polymorphic, and is apparently associated with intergenic heterodimer formation with GOT-3 products. Along with a fifth isoenzyme commonly expressed in pollen only, GOT-4 has been ignored in our analyses.

(d) GDH (Glutamate dehydrogenase): GDH isoenzymes appear to be encoded at two loci in this species. GDH, which is associated with the faster bands on these gels, is polymorphic for 3 alleles. The most common allele, GDH 1 , is the slowest while GDH 2 and GDH 3 are progressively faster. GDH $1 / 2$ and GDH $2 / 3$ heterozygotes form blurred bands from diploid homogenates and are represented as paired and sharply defined homomer bands in pollen channels. GDH 1/3 heterozygotes have not been observed in native materials. A second enzyme forms a band slower than GDH in GDH assayed gels. It is also often associated with a ladder of slower and increasingly faint bands, especially in diploid tissue channels. Pollen channels are usually clearer for this enzyme, although the band is often not sharp. This band has proven to be identical with, and predicted by, $\mathrm{ADH}$; it is regarded as an artefact, and has been ignored.

(e) ShDH (Shikimate dehydrogenase): This assay yielded evidence of a single locus which was polymorphic for two alleles in one population. The two alleles are clearly but not greatly different in mobilities. Electrophoretograms of diploid tissues are somewhat confused by shadow bands occurring above and below the main zones of activity, while the haploid (pollen) tissue yields either empty channels or channels showing only a lower shadow band. We are unable to determine whether a second locus is present nor whether the enzyme is monomeric or otherwise.

(f) IDH (Isocitrate dehydrogenase). This dimeric enzyme is encoded by two alleles at a single locus in our materials (fig. 2). The common allele, IDH 1 , is faster than IDH 2, which determines a single sharp band. IDH 1 homozygotes are characterised by a deeply staining sharp band and a less intense band just below. Zymograms of haploid 
FIGS. 1-4. Starch gel electrophoretograms of Isotoma petraea. In each figure, the genotype of each specimen is indicated at top for each locus recognised. The position of the homomer corresponding to each allele at each locus is indicated at the sides, by arrows, and the approximate position of the origin is indicated $(O) . B=$ bud (diploid tissue homogenate), $\mathbf{P}=$ pollen (haploid tissue homogenate).

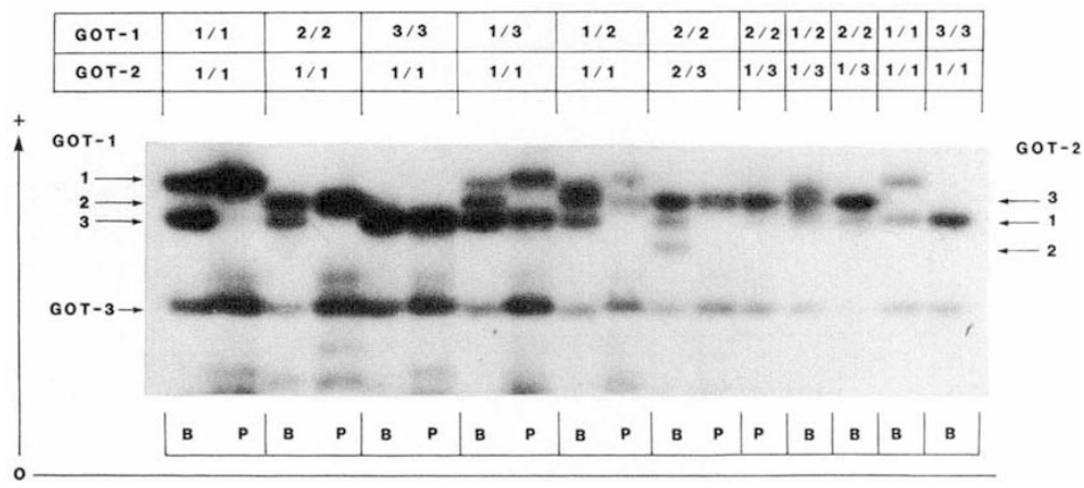

FIG. 1. GOT: Glutamate oxaloacetate transaminase. Three loci. Got-3 monomorphic. Got-2 not expressed in pollen; 3 alleles, dimeric. Got-1 expressed in bud and pollen, 3 alleles, dimeric. Got-1 3 comigrates with Got-2 1; Got-1 2 comigrates with Got-2 3. Additional blurred bands are associated with additional but unresolved loci.

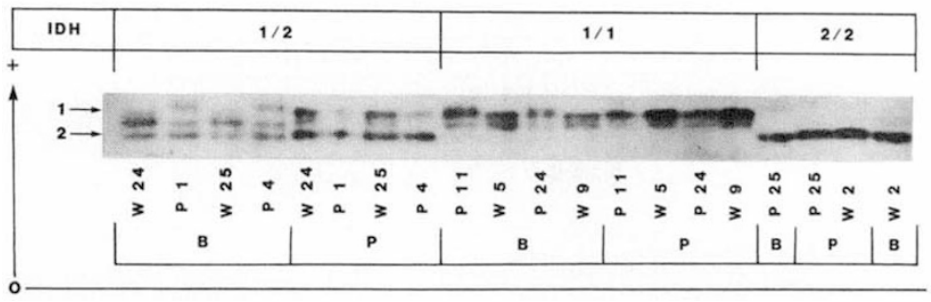

FIG. 2. IDH: Isocitrate dehydrogenase. One locus, two alleles, dimerous protein. The fast isoenzyme is associated with a shadow band, both in pollen and diploid tissue. The heterozygote pollen patterns are all similar and include the homomer bands and the fast homomer shadow, the heterozygote tissue patterns exhibit a pronounced heteromer band and population specific variation in relation to the fast homomer band and its shadow. $\mathrm{W} 2,5,9,24$ and 25:5 plants from Wargangering; $P 1,4,11,24,25: 5$ plants from Pigeon Rock. 


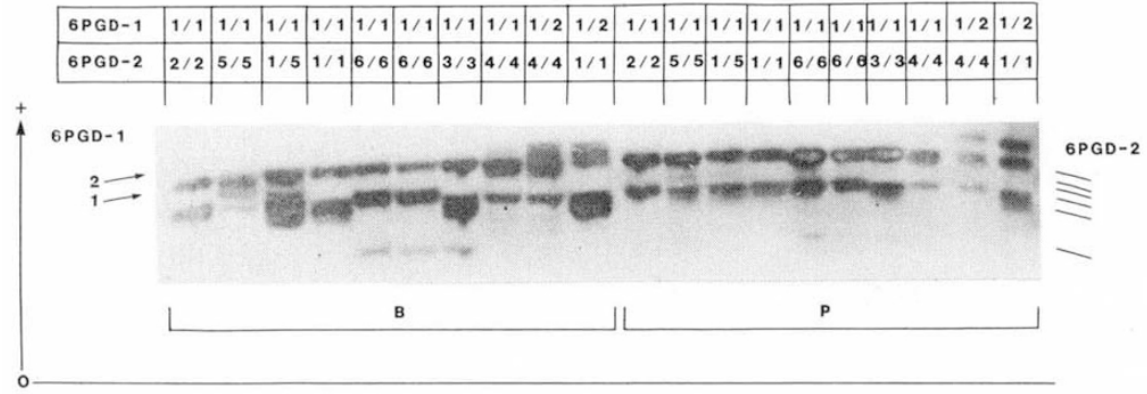

FIG. 3. 6PGD: 6-Phosphogluconate dehydrogenase. Two loci, oligomerous. In 6PGD-1 (upper band), two alleles, their homomer bands resolved in pollen at right. In $6 P G D-2$, a variety of phenotypes in diploid tissue electrophoretograms, but considerably more uniformity in pollen electrophoretograms. The same ten plants used for diploid phenotypes at left are repeated, as pollen samples, at right. Note the slow sharp bands in channels 5, 6 and 7 (repeated, but more faintly, in the corresponding pollen channels), which also appear after PGM assay. 6PGD-2 was taken to be monomorphic because of its relative uniformity in pollen samples.

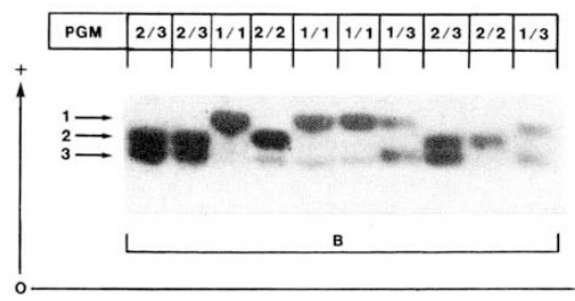

FIG. 4. PGM: Phosphoglucomutase. One locus, 3 alleles, monomerous protein. These are the same 10 plants used in the 6PGD illustration, laterally inverted. Note the slow "6PGD" band in channels 4,5 and 6 comigrating with PGM 3. 
and diploid extracts from homozygotes are similar but the heterozygotes are unusual and may show population specific differences in diploid tissue extracts, whereas their pollen extracts are similar and yield the two homodimerous bands characterising the homozygotes separately. Thus, in both Wargangering and Pigeon Rock diploid heterozygote tissue samples, the heterodimerous bands are quite distinct, while the homodimer and other bands combine to provide distinctive patterns. It is not known whether these differences are due to population specific differences, for example, in post-translational procedures, or to electrophoretically neutral mutations differentially recognisable by a common "post-translational" procedure. In this first analysis, we have ignored the genetic differences implied by these differences in heterozygote electrophenotypes.

(g) 6PGD (6-Phosphogluconate dehydrogenase): Two loci encoded these dimeric (or multimeric) isoenzymes (fig. 3). 6PGD-1 encodes the faster enzymes and is polymorphic for two alleles. Like IDH, $6 P G D-2$ proves to be almost monomorphic in pollen, but it encodes a complex array of phenotypes in diploidy. At least six basic phenotypes may be observed in diploid homogenates where one, two or more bands may be observed which are additional to, and may be faster than or slower than, and distinct from or in smeared association with, the corresponding haploid band. Heterozygotes appear to be the sum of their corresponding homozygotes. The phenotypic diversity in $6 P G D-2$ is, again, possibly due to various post-translational modifications of a single allele. $6 P G D-2$ is here classified as a monomorphic locus on the basis of its relative constancy in pollen homogenates, while the genetic diversity implied by its phenotypic diversity in diploidy has been ignored. It is of interest to note that one diploid phenotype of $6 P G D-2$ which has a "post-translational" band of very reduced mobility both in diploid and haploid channels, is associated with aberrant activity in PGM gels at a position comparable to that slow band.

(h) PGM (Phosphoglucomutase): Two loci encode PGM isoenzymes in Isotoma petraea but one of them, the faster, stains very slowly and faintly in our hands, and has been ignored. At the remaining locus, three alleles encoding monomeric allozymes have been observed (fig. 4). The enzyme assays easily from both haploid and diploid tissues.

(i) LAP (Leucine aminopeptidase): As with PGM, two loci encode these isoenzymes. One of them stains only faintly, but sufficiently to cause brief confusion with the better staining polymorphic LAP locus, and has been ignored. Four alleles at the LAP locus encode the monomeric allozymes. The enzyme assays easily from both haploid and diploid tissue.

(j) EST (Esterase): Populations of Isotoma petraea tend to be characterised by their own constellation of esterase phenotypes. Utilisation of this diversity in population studies awaits formal genetic analysis.

In summary, ten assay procedures have permitted the identification of 13 loci in Isotoma petraea, 9 polymorphic and 4 monomorphic in the sample surveyed. 
TABLE 1

Summary of the allozymic variation in natural population samples of Isotoma petraea for 13 loci. The sample size varied between population, and within populations variable numbers of plants were assayed for the different enzymes. MAX = number of plants assayed for the best analysed enzyme in that sample; $M I N=$ conversely, for the worst analysed enzyme; $M E A N=$ average number of plants in samples from that population over all enzymes surveyed. $H E T=$ average individual heterozygosity based on Hardy-Weinberg expectations (EXP) and observed $(O B S)$. Polymorphic loci detailed according to genotypic constitutions, $+=$ common allele in that sample, $m=$ rare allele in that sample; where more than 2 alleles occur in polymorphic samples, the observed genotypes are given in detail (3-Mile Rock LAP and PGM).

\begin{tabular}{lccc}
\hline & Sample Size & HET & Polymorphic loci \\
Population & MAXMEAN MIN & EXP OBS & Locus $t /++/ \mathrm{M}^{2} \mathrm{M}$ \\
\hline
\end{tabular}

(A) Structural homozygotes

\begin{tabular}{|c|c|c|c|c|c|c|c|c|c|}
\hline Yackeyackine Soak & 29 & 15.69 & 7 & 0 & 0 & & & & \\
\hline Gnarlbine Rock & 20 & $15 \cdot 62$ & 9 & 0.027 & 0.012 & $G O T-1$ & 14 & 3 & \\
\hline \multirow[t]{2}{*}{ Boorabbin } & 20 & $16 \cdot 31$ & 12 & 0.060 & 0.019 & GOT-1 & 15 & 2 & 3 \\
\hline & & & & & & ADH & 8 & 2 & 4 \\
\hline Bullabulling & 13 & 12.08 & 9 & 0.047 & 0.033 & $\begin{array}{l}\text { PGM } \\
\text { GDH }\end{array}$ & $\begin{array}{r}10 \\
7\end{array}$ & $\begin{array}{l}2 \\
3\end{array}$ & \\
\hline Mt Caudan & 9 & $6 \cdot 16$ & 1 & 0 & 0 & & & & \\
\hline Victoria Rock & 30 & $17 \cdot 23$ & 5 & 0.020 & 0.013 & $G O T-1$ & 23 & 5 & \\
\hline \multirow[t]{3}{*}{ Yellowdine } & 30 & 25.85 & 17 & 0.041 & 0.013 & $G O T-1$ & 23 & 3 & \\
\hline & & & & & & PGM & 27 & 0 & \\
\hline & & & & & & GDH & 24 & 2 & \\
\hline \multirow[t]{2}{*}{ Wargangering } & 33 & 30.62 & 26 & 0.043 & 0.019 & $G O T-1$ & 29 & 3 & \\
\hline & & & & & & IDH & 20 & 5 & \\
\hline Wagga Rock & 5 & 5 & 5 & 0.025 & $0 \cdot 030$ & 6PGD-1 & 3 & 2 & \\
\hline "Iron Knob Major" & 1 & 1 & 1 & 0 & $\mathbf{0}$ & & & & \\
\hline Rainy Rocks & 1 & 1 & 1 & 0.077 & $0 \cdot 154$ & $G O T-1$ & $\mathbf{0}$ & 1 & \\
\hline "Rainy Rocks Major" & 1 & 1 & 1 & 0 & $\mathbf{0}$ & & $\mathbf{0}$ & & \\
\hline \multicolumn{10}{|l|}{ (B) Complex hybrids } \\
\hline \multirow[t]{4}{*}{ Pigeon Rock } & 24 & $22 \cdot 54$ & 21 & $0 \cdot 109$ & 0.066 & $G O T-1$ & 10 & 4 & \\
\hline & & & & & & PGM & 12 & 12 & \\
\hline & & & & & & GDH & 20 & 1 & \\
\hline & & & & & & IDH & 10 & 3 & \\
\hline The Humps & 11 & $5 \cdot 31$ & 3 & 0.076 & $0 \cdot 154$ & & & & \\
\hline Graham Rocks & 13 & 10.85 & 9 & 0.088 & 0.162 & $6 P G D-1$ & 8 & 1 & \\
\hline Mt Arrowsmith & 10 & $7 \cdot 46$ & 2 & 0.077 & $0 \cdot 154$ & & & & \\
\hline Burracobbing & 7 & 6.31 & 6 & 0.115 & 0.220 & LAP & 1 & 6 & \\
\hline Yorkakine & 5 & $4 \cdot 0$ & 2 & 0.077 & 0.154 & & & & \\
\hline Mt Stephens & 7 & 6.92 & 6 & 0.072 & $0 \cdot 128$ & GDH & 2 & 4 & \\
\hline Elachbutting & 8 & 5.92 & 3 & 0.154 & $0 \cdot 308$ & & & & \\
\hline Berringbooding & 4 & $3 \cdot 23$ & 2 & 0.154 & 0.308 & & & & \\
\hline Baladjie & 6 & $5 \cdot 46$ & 4 & 0.154 & 0.308 & & & & \\
\hline Yanneymooning & 5 & $4 \cdot 31$ & 3 & 0.154 & $0 \cdot 308$ & & & & \\
\hline Waddouring & 5 & $4 \cdot 31$ & 4 & $0 \cdot 154$ & $0 \cdot 308$ & & & & \\
\hline \multirow[t]{3}{*}{ Police Rock } & 9 & 8.08 & 8 & 0.110 & 0.193 & $G O T-1$ & 3 & 5 & \\
\hline & & & & & & & 1 & 8 & \\
\hline & 14 & $9 \cdot 46$ & 4 & $0 \cdot 126$ & $0 \cdot 242$ & GDH & 6 & 1 & \\
\hline Muntadgin & 12 & $8 \cdot 85$ & 3 & $0 \cdot 115$ & $0 \cdot 230$ & & & & \\
\hline Nangeen & 5 & $4 \cdot 46$ & 2 & 0.123 & 0.246 & GDH & 4 & 1 & \\
\hline Mt Stirling S/E & 14 & $10 \cdot 08$ & 8 & 0.154 & $0 \cdot 302$ & $G O T-1$ & 1 & 13 & \\
\hline Merredin & 12 & 8.69 & 4 & 0.154 & 0.308 & & & & \\
\hline Moorine Rocks & 25 & $16 \cdot 15$ & 3 & $0 \cdot 154$ & 0.308 & & & & \\
\hline Warrachuppen & 4 & $3 \cdot 85$ & 3 & 0.154 & $0 \cdot 308$ & & & & \\
\hline Keokanie & 15 & $12 \cdot 38$ & 3 & 0.192 & 0.385 & & & & \\
\hline
\end{tabular}


TABLE 1 (contd.)

\begin{tabular}{|c|c|c|c|c|c|c|c|c|}
\hline \multirow{3}{*}{$\frac{\text { Population }}{\text { South Nullanulla }}$} & \multirow{2}{*}{\multicolumn{3}{|c|}{$\begin{array}{c}\text { Sample Size } \\
\text { MAXMEAN MIN }\end{array}$}} & \multirow{2}{*}{$\begin{array}{l}\text { HET } \\
\text { EXP OBS }\end{array}$} & \multicolumn{3}{|c|}{ Polymorphic loci } & \multirow[b]{2}{*}{$\mathrm{M} / \mathrm{M}$} \\
\hline & & & & & & & $+/ \mathrm{M}$ & \\
\hline & 12 & $7 \cdot 38$ & 2 & $0.154 \quad 0.308$ & & & & \\
\hline Mt Hampton & 20 & 15.92 & 8 & $0.115 \quad 0.230$ & & & & \\
\hline \multirow[t]{6}{*}{3 Mile-Rock } & 27 & $25 \cdot 54$ & 23 & $0.193 \quad 0.304$ & $G O T-1$ & 18 & 7 & 2 \\
\hline & & & & & $G O T-2$ & 2 & 25 & 0 \\
\hline & & & & & & $1 / 2$ & $2 / 3$ & $3 / 3$ \\
\hline & & & & & LAP & & & \\
\hline & & & & & & $1 / 1$ & $1 / 3$ & $2 / 3$ \\
\hline & & & & & PGM & 1 & 22 & 3 \\
\hline
\end{tabular}

(ii) The survey

The population analyses are summarised in tables 1 and 2 . The distribution of genetic variation amongst the structurally homozygous (7II) (or "floating interchange") populations and the complex hybrid $(\odot)$ populations was distinctly different.

The floating interchange populations were composed mainly of allozymic homozygotes; in 1875 individual observations, only 35 heterozygote patterns were seen $(\mathrm{P}[\mathrm{HET}]=0 \cdot 019)$. whereas in 2827 individual observations on complex hybrid material, 662 heterozygote patterns were observed $(\mathrm{P}[\mathrm{HET}]=0 \cdot 234)$. Allozyme heterozygosity among the complex hybrids was thus 12.5 times that among structural homozygotes.

Within the floating interchange populations, the low frequency of heterozygotes was less than would be expected on Hardy-Weinberg predictions. Because of the small sample sizes, only two population samples (ADH in Boorabbin and IDH in Wargangering) exhibited statistically significant heterozygote shortfalls, but overall, thirty rare allele homozygotes and 35 heterozygotes were observed. Thus, rare alleles in these populations were almost twice as likely to occur in homozygotes $(0.63)$ as in heterozygotes $(0 \cdot 37)$.

Within the complex hybrid populations, allozyme heterozygotes were abundant and in 83 instances of alleleic variation occurring within such populations, $67(=0.7$ per cent) exhibited fixed hybridity. Amongst the 16 polymorphisms heterozygotes constituted 46.6 per cent of the total.

The highly polymorphic Pigeon Rock population was unique amongst complex hybrid populations in that its average heterozygosity was less than Hardy-Weinberg expectations. The 3-mile Rock population was also highly polymorphic, but it exhibited the typically elevated average heterozygosity of complex hybrid populations.

The polymorphic loci themselves were variable with respect to the degree of variation they exhibited, and no electrophenotype was diagnostic of complex hybridity. GOT-1 was the most variable locus, with six of the 12 floating interchange populations exhibiting polymorphism. Each of the 3 alleles observed at this locus was the most common allele in at least one such population, while in the complex hybrids, 5 situations ( $2^{*} 21^{*} 1,2$ 2,3 see table 2 ) were observed. LAP was the locus most nearly diagnostic of complex hybridity; excluding the variable Pigeon Rock and 3-mile Rock populations, only two homozygotes (one $1 / 1$, one $3 / 3$ ) 
TABLE 2

Common alleles in population samples of Isotoma petraea for the 9 polymorphic loci. * polymorphic sample with the indicated allele most common. See table 1 for sample genotypic constitution. Where two alleles are equally frequent, as in fixed hybridity, both alleles are indicated.

GOT-1 GOT-2 LAP PGM GDH ADH IDH ShDH 6PGD-1

(a) Structural homozygotes

$\begin{array}{lccccccccc}\text { Yackeyackine Soak } & 1 & 1 & 3 & 1 & 1 & 1 & 1 & 1 & 1 \\ \text { Gnarlbine Rock } & 1^{*} & 1 & 3 & 1 & 1 & 1 & 1 & 1 & 1 \\ \text { Boorabbin } & 1^{*} & 1 & 3 & 1 & 1 & 2^{*} & 1 & 1 & 1 \\ \text { Bullabulling } & 1 & 1 & 3 & 1^{*} & 1^{*} & 1 & 1 & 1 & 1 \\ \text { Mt Caudan } & 2 & 1 & 4 & 1 & 1 & 1 & 1 & 1 & 1 \\ \text { Victoria } & 1^{*} & 1 & 3 & 1 & 1 & 1 & 1 & 1 & 1 \\ \text { Yellowdine } & 3^{*} & 1 & 3 & 1^{*} & 1^{*} & 1 & 1 & 1 & 1 \\ \text { Wargangering } & 1^{*} & 1 & 3 & 1 & 1 & 1 & 1^{*} & 1 & 1 \\ \text { Wagga Rock } & 1 & 1 & 3 & 1 & 1 & 1 & 1 & 1 & 1^{*} \\ \text { "Iron Knob Major" } & 2 & 1 & 3 & 2 & 1 & 1 & 2 & 1 & 1 \\ \text { Rainy Rocks } & 1,2^{*} & 1 & 3 & 1,2^{*} & 1 & 1 & 1 & 1 & 1 \\ \text { "Rainy Rocks Major" } & 2 & 1 & 3 & 2 & 1 & 1 & 1 & 1 & 1\end{array}$

(b) Complex hybrids

\begin{tabular}{lccccccccc} 
Pigeon Rock & $2^{*}$ & 1 & 3 & $1^{*}$ & $1^{*}$ & 1 & $2^{*}$ & 1 & 1 \\
The Humps & 2 & 1 & 1,3 & 1,3 & 1 & 1 & 1 & 1 & 1 \\
Graham Rocks & 2 & 1 & 1,3 & 3 & 1 & 1 & 1 & 1 & $1^{*}$ \\
Mt Arrowsmith & 2 & 1 & 1,3 & 1,3 & 1 & 1 & 1 & 1 & 1 \\
Burracobbing & 2 & 1 & $3^{*}$ & 1,3 & 1,2 & 1 & 1 & 1 & 1 \\
Yorkrakine & 2 & 1 & 1,3 & 3 & 1,2 & 1 & 1 & 1 & 1 \\
Mt Stephens & 2 & 1 & 1,3 & 2 & $2^{*}$ & 1 & 1 & 1 & 1 \\
Elachbutting & 1,2 & 1 & 1,3 & 1,3 & 1,2 & 1 & 1 & 1 & 1 \\
Berringbooding & 1,2 & 1 & 1,3 & 1,3 & 1,2 & 1 & 1 & 1 & 1 \\
Baladjie & 1,2 & 1 & 1,3 & 1,3 & 1,2 & 1 & 1 & 1 & 1 \\
Yanneymooning & 1,2 & 1 & 1,3 & 1,3 & 1,2 & 1 & 1 & 1 & 1 \\
Waddouring & 1,2 & 1 & 1,3 & 1,3 & 1,2 & 1 & 1 & 1 & 1 \\
Police Rock & $1^{*}$ & 1 & $1 *$ & 1,3 & 2 & 1 & 1 & 1 & 1 \\
Mt Stirling & 1,2 & 1 & 1,3 & 1,3 & $2^{*}$ & 1 & 1 & 1 & 1 \\
Muntadgin & 1,2 & 1 & 1,3 & 1,3 & 1 & 1 & 1 & 1 & 1 \\
Nangeen & 1,2 & 1 & 1,3 & 3 & $2^{*}$ & 1 & 1 & 1 & 1 \\
Mt Stirling S/E & $1^{*}$ & 1 & 1,3 & 2,3 & 1,2 & 1 & 1 & 1 & 1 \\
Merredin & 2,3 & 1 & 1,3 & 1,3 & 1,2 & 1 & 1 & 1 & 1 \\
Moorine Rocks & 2 & 2,3 & 1,3 & 2,3 & 1,2 & 1 & 1 & 1 & 1 \\
Warrachuppen & 2 & 1 & 1,3 & 2,3 & 1,2 & 1 & 1 & 1 & 1,2 \\
Keokanie & 2 & 1,3 & 1,3 & 1,3 & 1,2 & 1 & 1 & 1 & 1,2 \\
South Nullanulla & 2 & 1,3 & 1,3 & 2,3 & 1 & 1 & 1 & 1 & 1,2 \\
Mt Hampton & 2 & 1 & 1,3 & 3 & 1 & 1 & 1 & 1,2 & 1,2 \\
3 Mile-Rock & $2^{*}$ & $1 *$ & $2^{*}$ & $2^{*}$ & 1,2 & 1 & 1 & 1 & 1 \\
Universal Common & & & & & & & & & \\
$\quad$ Allele & 2 & 1 & 3 & 1 & 1 & 1 & 1 & 1 & 1 \\
\hline
\end{tabular}

were observed along with $108(1 / 3)$ heterozygotes. The LAP locus was of further interest in that it exhibited the only instance of unique allele fixation, of LAP 4, in the Mt Caudan 7II population.

Each of the loci which exhibited fixed heterozygosity in some complex hybrid populations also exhibited homozygote monomorphism or polymorphism in others. Where population monomorphism was exhibited at such loci, the allele concerned was the universal common allele in 74 of 80 $(=92.5$ per cent) cases. Five complex hybrid populations were fixed for 
the rare PGM 3 allele, and one for the rare GDH 2. Nine of the 16 polymorphisms in complex hybrid populations had the universal rare allele most common.

\section{Discussion}

Since allozyme heterozygosity in Isotoma petraea is some 12.5 times greater in complex hybrid populations than in structurally homogyzous (or floating interchange) populations, there can be little doubt that the evolution of complex hybridity in this species has been associated with a pursuit of hybridity. Allozyme heterozygosity levels in the polymorphic Pigeon Rock complex hybrid population, at 0.07 , are somewhat elevated above that of the structural homozygotes $(0.02)$ but less than that of the complex hybrids generally $(0 \cdot 23)$. This relationship is perfectly in keeping with the proposal that complex hybridity arose on Pigeon Rock and has migrated in a generally south-westerly direction through other populations, the genetic system being progressively and sequentially improved by interpopulational hybridisations resulting in the generation of new levels of genic hybridity, new chromosome rearrangements, new lethals, and the entrappment of this hybridity in stable complex hybridity, as outlined by James (1970). We suspect that the allozymically and cytologically (James 1970) polymorphic 3-mile Rock population represents a recent invasion of complex hybridity into an erstwhile 7II population.

In this survey, the Pigeon Rock complex hybrids were PGM 1/3 heterozygotes, and this apparently represents the first locus, amongst those we have surveyed, locked into fixed hybridity. PGM $1 / 3$ heterozygosity was found in 13 of the 22 larger ringed complex hybrid populations (excluding 3 -mile Rock) but is replaced by $2 / 3$ heterozygosity in 4 , and $3 / 3$ homozygosity in 5 populations, including the southern-most, Graham Rock. If the complexes only expand during their evolution, then the replacement of PGM $1 / 3$ heterozygosity by $2 / 3$ heterozygosity, and by $3 / 3$ homozygosity, indicates the replacement of one heterozygous segment in the ring by another, and the PGM locus, merely a flag on this segment, fortuitously relabelled. Similarly, the LAP 1/3,3/3 polymorphism in the Burracobbing population, the LAP $1 / 3,1 / 1$ polymorphism on Police Rock, the GOT-1 $1 / 2,1 / 1$ polymorphisms on Police Rock and Mt Stirling S/E, and the GDH 1/2,2/2 polymorphisms on Mt Stephens, Mt Stirling and Nangeen Hill indicate segmental replacements with continuing segmental hybridity rather than any loss of hybridity. Indeed, in a mature complex hybrid population system, on this basis, if the frequency of an allele amongst the primitive structurally homozygous ancestors was $p$, then we might expect $p^{2}$ of the complex hybrid derivatives to be homozygous for that marker. And consequently, it is not surprising that Oenothera complex hybrids are almost as depauperate in allozyme variability as are their structurally homozygous brethren.

The evolution of complex hybridity clearly demonstrates the ability of natural selection to assemble genetic systems capable of maximising genetic heterozygosity in selfed progeny and thus it also demonstrates the heuristic adaptive superiority of heterozygous genotypes, at least in Isotoma petraea. While this favoured heterozygosity may be marked by fixed allozyme hybridity, it evidently may still exist, vide supra, in allozymically homozygous complex hybrids. Thus, we may ask whether heterozygote superiority is 
also a feature in the structurally, homozygous ancestral populations which are highly depauperate for allozyme heterozygosity. If so, then the terminal localisation of chiasmata, high fecundity and small seed size in Isotoma are clearly adaptive devices in its genetic system ensuring an adequate yield $\left(\frac{1}{128}\right)$ of selfed seeds carrying parental levels of hybridity (James 1970,1982).

If allozyme genotype is only a convenient marker of chromosome segments and selectively inconsequential, the important hybridity pursued by natural selection must be elsewhere. It is of interest to note than in Isotoma petraea, some enzymes, e.g., IDH and 6PGD, have been observed to show electrophenotypic differences in diploidy and electrophenotypic identity in haploidy, over and above that attributable to heteromer formation, and one isoenzyme of $6 P G D-2$ appears to have enhanced biochemical capability. While exact descriptions of the biochemical capabilities and their genetic determination await further research, it is certainly possible that hybridity amongst genes determining secondary capabilities such as these may be of heuristic and evolutionary significance.

We conclude that the distribution of allozyme variation in Isotoma petraea conforms entirely with expectations based on a Darlingtonian interpretation of complex hybridity and of its evolution. This theory proposes that complex hybridity evolves in chromosomally preadapted inbreeding lineages as a consequence of natural selection favouring mechanisms enabling a more efficient pursuit of hybridity, and involves a progressive reduction in recombination. The Isotoma situation also provides an explanation for the relatively low levels of allozyme heterozygosity found by Levin and his colleagues in Oenothera complex hybrids.

Acknowledgements. We are especially indebted to Mr Dave Waldie and his support staff for horticultural assistance, Miss Fiona Webb for secretarial work and the Australian Research Grants Scheme for its continuing support.

\section{REFERENCES}

DARLINGton, C. D. 1958. The Evolution of Genetic Systems, 2nd Ed. Oliver and Boyd, London.

JAMES, S. H. 1965. Complex hybridity in Isotoma petraea. I. The occurrence of interchange heterozygosity, autogamy and a balanced lethal system. Heredity, 20, 341-353.

JAMES, S. H. 1970. Complex hybridity in Isotoma petraea. II. Components and operation of a possible evolutionary mechanism. Heredity, 25, 53-78.

JAMES, S. H. 1982. Coadaptation of the genetic system and the evolution of isolation among populations of Western Australian native plants. In Barigozzi, C., (ed.) Mechanisms of Speciation, Alan R. Liss, New York, pp. 461-470.

LEVIN, D. A. 1975. Genic heterozygosity and protein polymorphism among local populations of Oenothera biennis Genetics, 79, 477-491.

LEVY, M. AND LEVIN, D. A. 1975. Genetic heterozygosity and variation in permanent translocation heterozygotes of the Oenothera biennis complex. Genetics, 79, 493-512.

LINHART, Y. B., DAVIS, M. L. AND MITTON, J. B. 1981. Genetic control of allozymes of shikimate dehydrogenase in Ponderosa pine. Biochem. Genet., 19, 641-646.

NUMACHI, K. 1981. A simple method for preservation and scanning of starch gels. Biochem. Genet., 19, 233-236.

SELANDER, R. K.. SMITH, M. H., YANG, S. Y. AND JOHNSON, W. E. 1971. Biochemical polymorphism and systematics in the genus Peromyscus. I. Variation in the old-field mouse Peromyscus polionotus. pp. 49-70. 7103 Studies in Genetics VI. Univ. of Texas Publ.

SHAW, C. R. AND PRASAD, R. 1970. Starch gel electrophoresis of enzymes-a compilation of recipes. Biochem. Genet., 4, 297-320. 
WEEDEN, N. F. AND GOTTLIEB, L. D. 1979. Distinguishing allozymes and isozymes of phosphoglucoisomerase by electrophoretic comparisons of pollen and somatic tissues. Biochem. Genet., 17, 287-296. 